\title{
Evaluation of a novel approach to circulating tumor cell isolation for cancer gene panel analysis in patients with breast cancer
}

\author{
SOO JEONG LEE ${ }^{1 *}$, CHAM HAN LEE $^{1 *}$, SUNG HO CHOI ${ }^{1}$, SEI HYUN AHN ${ }^{2}$, \\ BYUNG HO SON ${ }^{2}$, JONG WON LEE ${ }^{2}$, JONG HAN YU ${ }^{2}$, NAK-JUNG KWON ${ }^{3}$, WOO CHUNG LEE ${ }^{3}$, \\ KAP-SEOK YANG ${ }^{3}$, DONG HYOUNG LEE ${ }^{1}$, DU YEOL HAN ${ }^{1}$, MI SO CHOI ${ }^{1}$, PYEONG-SOO PARK ${ }^{1}$, \\ HYUN KYUNG LEE ${ }^{1}$, MYOUNG SHIN KIM ${ }^{1}$, JINSEON LEE ${ }^{1}$ and BYUNG HEE JEON ${ }^{1}$
}

${ }^{1}$ Cytogen, Inc., Songpa-gu, Seoul 138-961; ${ }^{2}$ Department of Surgery, Asan Medical Center Affiliated to The University of Uslan College of Medicine, Songpa-gu, Seoul 138-736; ${ }^{3}$ Macrogen, Inc., Geumcheon-gu, Seoul 08511, Republic of Korea

Received July 24, 2015; Accepted November 11, 2016

DOI: $10.3892 / 01.2017 .5807$

\begin{abstract}
Liquid biopsy isolation of circulating tumor cells (CTCs) allows the genomic analysis of CTCs, which is useful in the determination of personalized cancer therapy. In the present study, CTCs from patients with breast cancer were enriched and successfully analyzed using cancer gene panel analysis. Blood samples from 11 patients with breast cancer were collected and CTCs enriched for using size-based filtration. The enriched CTCs were analyzed using immunofluorescence staining with antibodies directed against epithelial cell adhesion molecule (EpCAM) and cluster of differentiation 45. The genomic DNA of CTCs was extracted, amplified and 50 genes screened for mutations using the Ion AmpliSeq ${ }^{\mathrm{TM}}$ Cancer Hotspot Panel v2. EpCAM staining detected CTCs in 10/11 patients and the average CTC count was 3.9 in $5 \mathrm{ml}$ blood. The average purity of enriched CTCs was $14.2 \pm 29.4 \%$ and the average amount of amplified DNA was $28.6 \pm 11.9 \mu \mathrm{g}$. Catalogue Of Somatic Mutations In Cancer mutations were detected in the CTCs and included IDH2, TP53, NRAS, IDH1, PDGFRA, HRAS, STK11, EGFR, PTEN, MLH1, PIK3CA, CDKN2A, KIT and SMARCB1. In conclusion, a novel size-based filtration approach for the isolation of CTCs was evaluated and successfully applied for the genomic analysis of CTCs from patients with breast cancer.
\end{abstract}

Correspondence to: Dr Byung Hee Jeon, Cytogen, Inc., Garden 5 Works A-616, 52 Chungmin-ro, Songpa-gu, Seoul 138-961, Republic of Korea

E-mail: bhjeon@cytogenlab.com

*Contributed equally

Key words: breast cancer, circulating tumor cells, cancer gene panel analysis, liquid biopsy

\section{Introduction}

Circulating tumor cells (CTCs) are shed from primary and metastatic tumors, and maintain similar characteristics to tumor tissue (1). CTCs are present at a relatively low concentration of $1-10$ cells $/ 10 \mathrm{ml}$ of patients' blood (2). The majority of CTCs are defined as cytokeratin (CK) 8,18 and 19 positive and cluster of differentiation (CD) 45 negative nucleated cells (3).

The genomic characteristics of cells differ between metastatic and primary tumors, and metastases located at different sites within the same patient are heterogeneous (4). Therefore, primary tumor biopsies may not be representative of metastatic tumor genomes. Liquid biopsies, whereby CTCs and cell-free circulating tumor DNA (ctDNA) are genetically screened for mutations, has been suggested as a novel method to identify therapeutic targets for the treatment of drug resistant tumors. Liquid biopsy has the advantage of being non-invasive and allows for reproducible access to tumor cells, whilst providing real-time monitoring of tumor evolution throughout treatment. ctDNA originates from the necrotic or apoptotic cancer cells of patients, particularly patients who have undergone chemotherapy. CTCs are resistant to chemotherapy; consequently, the liquid biopsy of CTCs has been highlighted as an alternative tool to tumor tissue biopsy (5).

The rarity of CTCs has been a challenge to CTC research and several different CTC isolation technologies have been developed to overcome this issue. CTC isolation technologies can be distinguished into the following two categories: One based on physical properties, including size, deformability, density and electric charge; and the other on biological properties, such as cell surface marker proteins (6). CELLSEARCH $^{\circledR}$ (Janssen Diagnostics, LCC, South Raritan, NJ, USA) is the most well recognized CTC isolation technique and captures CTCs using an immunomagnetic separation method with an antibody directed against epithelial cell adhesion molecule (EpCAM) (7). The limitation of this method is the poor vailability of viable and intact cell specimens for use in downstream analysis. In addition, the ferrofluid used in CELLSEARCH technology causes dose-dependent cytotoxicity (8), and magnetic beads adversely affect cell proliferation and metabolism (9). Furthermore, 
EpCAM-positive selection is not suitable for the enrichment of CTCs with low EpCAM expression $(10,11)$.

Breast cancer is the most common type of malignancy in women. The Surveillance, Epidemiology and End Results Program of the National Cancer Institute (Bethesda, MD, USA) reports a breast cancer incidence rate of 123.8/10,000 population/year (12). Targeted therapy, which inhibits specific signaling pathways, is effective in the treatment of breast cancer. Herceptin ${ }^{\circledR}$ and Tykerb ${ }^{\circledR}$, which target the human epidermal growth factor receptor 2 (HER2) gene, are used in the treatment of breast cancer $(13,14)$. The genomic analysis of tumor cells is essential to make decisions regarding the selection of therapeutic targets for cancer treatment. In a recent study, tumor protein p53 (TP53) mutation was detected through the genetic analysis of CTCs from metastatic tumors in a patient with triple-negative breast cancer (15). In another recent study, CTCs were analyzed at single cell level, which identified the heterogeneity of phosphatidylinositol-4 5-bisphosphate 3-kinase catalytic subunit alpha (PIK3CA) mutations (16).

In the present study, a novel CTC isolation technique according to cell size, using a high-density microporous (HDM) chip (Cytogen GmbH Co., Wetzlar, Germany) and a white blood cell (WBC)-negative selection method was evaluated. In addition, a cancer gene panel analysis of the CTCs that were isolated using this technique was performed.

\section{Materials and methods}

Patient background. A total of 11 female patients with breast cancer from the Asan Medical Center affiliated to the University of Uslan College of Medicine (Seoul, Korea) were included in the present study. The median age of the patients was 44 years old (range, 34-56 years old). Cancer stage, and histologic and nuclear grade were evaluated based on the tumor-node-metastasis classification (17) of the American Joint Committee on Cancer (Table I). All medical data used in the present study were anonymized and obtained following approval of the present study by the Institutional Review Board of Asan Medical Center (Seoul, Korea) (clearance no. 2013-1048).

Blood collection and CTC enrichment process. Blood $(10 \mathrm{ml})$ from each patient was collected for a month (December 2014) in Acid Citrate Dextrose tubes (BD Vacutainer ${ }^{\circledR}$; BD Biosciences, San Jose, CA, USA) and processed within $4 \mathrm{~h}$. Each blood sample was divided in half, with the CTCs from one half undergoing immunofluorescent staining and the CTCs from the other undergoing cancer gene panel analysis. CTC isolation was performed using a SMART BIOPSY ${ }^{\mathrm{TM}}$ SYSTEM Isolation kit (cat no. CIKW10; Cytogen, Inc., Seoul, Korea). Blood samples were incubated with an antibody cocktail from the SMART BIOPSY SYSTEM Isolation kit (Cytogen, Inc.) against WBCs and red blood cells for $20 \mathrm{~min}$, and mixed with pre-activation buffer followed by density gradient centrifugation at $400 \times \mathrm{g}$ for $30 \mathrm{~min}$ at room temperature. The cell suspension containing CTCs was collected and gradually diluted with dilution buffer (Cytogen, Inc.). Diluted cell suspensions were filtered through a HDM chip (Cytogen,
Inc.) as previously described (18). Cells on the HDM chip were collected and transferred to a microtube. An EVETM Automated Cell counter (Nano EnTek, Inc., Seoul, Korea) was used to measure cell size prior to and following HDM chip filtration. For immunofluorescent staining, isolated cells were fixed on slides in $4 \%$ paraformaldehyde for $5 \mathrm{~min}$ at room temperature. For cancer gene panel analysis, isolated cells were pelleted and kept at $-80^{\circ} \mathrm{C}$ until required.

Immunofluorescence staining. Cells on slides were permeabilized with $0.2 \%$ Triton X-100 in PBS for $10 \mathrm{~min}$ and quenched with $0.3 \%$ hydrogen peroxide for $30 \mathrm{~min}$ at room temperature. Cells were then blocked with $1 \%$ bovine serum albumin in PBS for 30 min and incubated with primary antibodies for $90 \mathrm{~min}$ at $37^{\circ} \mathrm{C}$, followed by secondary antibody incubation at same condition. The primary antibodies used were mouse anti-EpCAM (dilution, 1:200; catalog no. \#2929; CST Biological Reagents Company Ltd., Shanghai, China) and rabbit anti-CD45 (dilution, 1:50; catalog no. SC53047; Santa Cruz Biotechnology, Inc., Dallas, TX, USA). EpCAM signaling was amplified using the $\mathrm{TSA}^{\mathrm{TM}}$ kit (catalog no. T20922; Thermo Fisher Scientific, Inc., Waltham, MA, USA), according to the manufacturer's protocol. The secondary antibody used against CD45 was goat anti-rabbit Alexa Fluor ${ }^{\circledR} 594$ (dilution, 1:100; catalog no. A11012; Invitrogen; Thermo Fisher Scientific, Inc.). The slides were mounted using Fluoroshield ${ }^{\mathrm{TM}}$ Mounting Medium with DAPI (ImmunoBioScience Corp., Mukilteo, WA, USA). Stained cells were observed and images captured using a fluorescent microscope (Eclipse Ti; Nikon Corporation, Tokyo, Japan) with a 400X objective. To identify EpCAM-positive and CD45-negative CTCs, the PC9 (EpCAM-positive) and KG-1 (CD45-positive) cell lines were used as positive controls.

Spike-in test with H358-green fluorescent protein cells for confirmation of CTC capture efficiency. A total of 100 H358-green fluorescent protein (GFP) cells were spiked into $1 \mathrm{ml}$ of healthy volunteers' blood, which underwent the same CTC isolation protocol described above. The isolated cell suspension was transferred to a new dish and the number of GFP-positive cells were counted under a fluorescent microscope (Eclipse Ti; Nikon Corporation) within $30 \mathrm{~min}$. Experiments were performed in triplicate. The CTC detection rate was determined as follows: CTC detection rate $(\%)=($ No. of CTCs detected in patients/total patient no.)x100. CTC purity was calculated as follows: CTC purity $(\%)=($ Detection of CTC no./total cell no.)x100.

MCF7 cell line culture as a positive control. MCF-7 cells were obtained from Asan Medical Center affiliated to the University of Uslan College of Medicine (Seoul, Korea), and were routinely maintained in RPMI-1640 medium (Gibco ${ }^{\circledR}$; Thermo Fisher Scientific, Inc.) supplemented with $10 \%$ fetal calf serum and $1 \%$ antibiotics at $37^{\circ} \mathrm{C}$ in humidified, concentrated $\mathrm{CO}_{2}(5 \%)$ atmosphere.

Whole genome amplification (WGA). CTC cell pellets from patients were amplified using the REPLI-g Single Cell kit (Qiagen Inc., Valencia, CA, USA) according to the manufacturer's protocol. Briefly, cell pellets were mixed with 
denaturing buffer and incubated at $65^{\circ} \mathrm{C}$ for $10 \mathrm{~min}$. Following the addition of stop solution, denatured DNA samples were mixed with REPLI-g sc DNA polymerase and reaction buffer, and incubated at $30^{\circ} \mathrm{C}$ for $8 \mathrm{~h}$, followed by further incubation at $65^{\circ} \mathrm{C}$ for $3 \mathrm{~min}$.

Cancer gene panel analysis. Genomic mutations were analyzed using the Ion AmpliSeq ${ }^{\mathrm{TM}}$ Cancer Hotspot Panel v2 (Thermo Fisher Scientific, Inc.), a next-generation sequencing assay that identifies multiple somatic mutations [2,800 Catalogue of Somatic Mutations in Cancer (COSMIC) mutations across 50 genes]. Genomic DNA was amplified using the aforementioned WGA protocol and the amplicons were purified using the Agencourt AM-Pure XP kit (Beckman Coulter, Inc., Brea, CA, USA), followed by end repair and ligation using Ion Xpress ${ }^{\mathrm{TM}}$ Barcode Adapters kit (catalog no., 4471250; Thermo Fisher Scientific, Inc.). The median fragment size and concentration of the final amplicon library were detected using a BioAnalyzer 2100 with Agilent High Sensitivity DNA kit (Agilent Technologies, Inc., Santa Clara, CA, USA).

The amplicon library was diluted to $10 \mathrm{pM}$ with TE buffer and $5 \mu \mathrm{l}$ of the library was used for automatic PCR; the Ion OneTouch $^{\mathrm{TM}}$ system (catalog no. 4474779; Invitrogen; Thermo Fisher Scientific, Inc.) performed emulsion PCR reactions using Ion PGM ${ }^{\mathrm{TM}}$ Template OT2 200 kit following the manufacturer's protocol. The following cycling conditions were used: $80^{\circ} \mathrm{C}$ for $3 \mathrm{~min}$; 18 cycles of $\left(99^{\circ} \mathrm{C}\right.$ for $20 \mathrm{sec}, 58^{\circ} \mathrm{C}$ for $30 \mathrm{sec}, 72^{\circ} \mathrm{C}$ for $1 \mathrm{~min}, 99^{\circ} \mathrm{C}$ for $20 \mathrm{sec}, 56^{\circ} \mathrm{C}$ for $30 \mathrm{sec}$ and $70^{\circ} \mathrm{C}$ for $\left.1 \mathrm{~min}\right)$; and 10 cycles of $\left(99^{\circ} \mathrm{C}\right.$ for $20 \mathrm{sec}$, and $58^{\circ} \mathrm{C}$ for elongated durations from $3-20 \mathrm{~min}$ ) with heat cover at $85^{\circ} \mathrm{C}$. Subsequently, the emulsion PCR product was enriched using Dynabeads ${ }^{\circledR}$ MyOne $^{\mathrm{TM}}$ Streptavidin C1 beads (Invitrogen; Thermo Fisher Scientific, Inc.). The final enriched ion spheres were mixed with a sequencing primer and polymerase, and loaded onto five 316 chips (Ion PGM ${ }^{\text {тм }}$ Sequencing 200 kit v2) in total. Base calling was generated using Torrent Suite software (version 3.0; Thermo Fisher Scientific, Inc.) with tmap-f3 indexing. BAM and FASTQ alignment files were generated based on the base calling results and were used for variant calling, including single nucleotide polymorphisms and insertions/deletions.

Statistical analysis. The software used for statistical analysis was IBM SPSS version 24 (IBM Corp., Armonk, NY, USA) and Student's t-test was performed. $\mathrm{P}<0.05$ was considered to indicate a statistically significant difference.

\section{Results}

HDM cell recovery rate and CTC size. To evaluate the cell recovery rate of the HDM chip used, a spike-in test using H358-GFP cells was performed. This identified a cell recovery rate of $83.5 \%$. (Fig. 1A). Furthermore, the average CTC size in the patients' blood prior to and following HDM chip filtration was compared. The average CTC size prior to filtration was $7.84 \pm 0.87 \mu \mathrm{m}$, which increased to $13.99 \pm 3.67 \mu \mathrm{m}$ following filtration (Fig. 1B). This is in agreement with a previous study that reported that the average size of CTCs from patients with breast cancer was $13.1 \mu \mathrm{m}$ (19), in addition to confirming that
Table I. Clinicopathological characteristics of 11 female patients with breast cancer.

$\begin{array}{lr}\begin{array}{l}\text { Clinicopathological } \\ \text { characteristic }\end{array} & \text { Number of } \\ & \text { patients }(\%)\end{array}$

$\begin{array}{ll}\text { TNM stage } & \\ \text { IA } & 1(9.1) \\ \text { IIB } & 5(45.5) \\ \text { IIIA } & 3(27.3) \\ \text { IIIB } & 0(0) \\ \text { IIIC } & 2(18.2)\end{array}$

Histological grade

2

$10(90.9)$

3

Nuclear grade

2

$10(90.9)$

3

$1(9.1)$

TNM, tumor-node-metastasis. Histologic and nuclear grades are according to the Scarff-Bloom-Richardson grading system (17).

Table II. Efficiency of circulating tumor cell isolation and whole genome amplification.

\begin{tabular}{lc}
\hline Measure & Value \\
\hline Total cell number & $184.7 \pm 207.0(1-636)$ \\
CTC (EpCAM-positive cell) count & $3.9 \pm 5.5(0-19)$ \\
CTC detection rate $(\%)$ & $90.9 \pm 0.3$ \\
CTC purity $(\%)$ & $14.2 \pm 29.4(0-100)$ \\
DNA concentration $(\mathrm{ng} / \mu \mathrm{l})$ & $571.4 \pm 171.9(89-688)$ \\
Total DNA $(\mu \mathrm{g})$ & $28.6 \pm 11.9(4.9-37.8)$ \\
\hline
\end{tabular}

All results are presented as the mean \pm standard deviation (range). EpCAM, epithelial cell adhesion molecule.

a HDM chip with a $6.5 \mu \mathrm{m}$ pore size effectively enriched for CTCs in the present study.

Efficiency of CTC isolation and results of WGA. EpCAM-positive CTCs were detected in the blood samples of patients with breast cancer (Fig. 2). PC9 (EpCAM-positive) and KG-1 (CD45-positive) cells were used as positive controls during this immunostaining, in addition to WBCs. The average CTC count from the 11 patients was 3.9 in $5 \mathrm{ml}$ blood and the detection rate was $90.9 \%$ (10 out of 11) (Table II). The purity of CTCs isolated with the protocol used in the current study was $14.2 \%$ (range, 0-100; Table II). The average amount of total DNA obtained following WGA was $28.6 \mu \mathrm{g}$ (range, 4.9-37.8 $\mu \mathrm{g}$; Table II). Reference coverage (the average number of reads that cover each reference position) analysis demonstrated complete amplification of CTC DNA compared with the MCF7 breast cancer cell line (Fig. 3). 

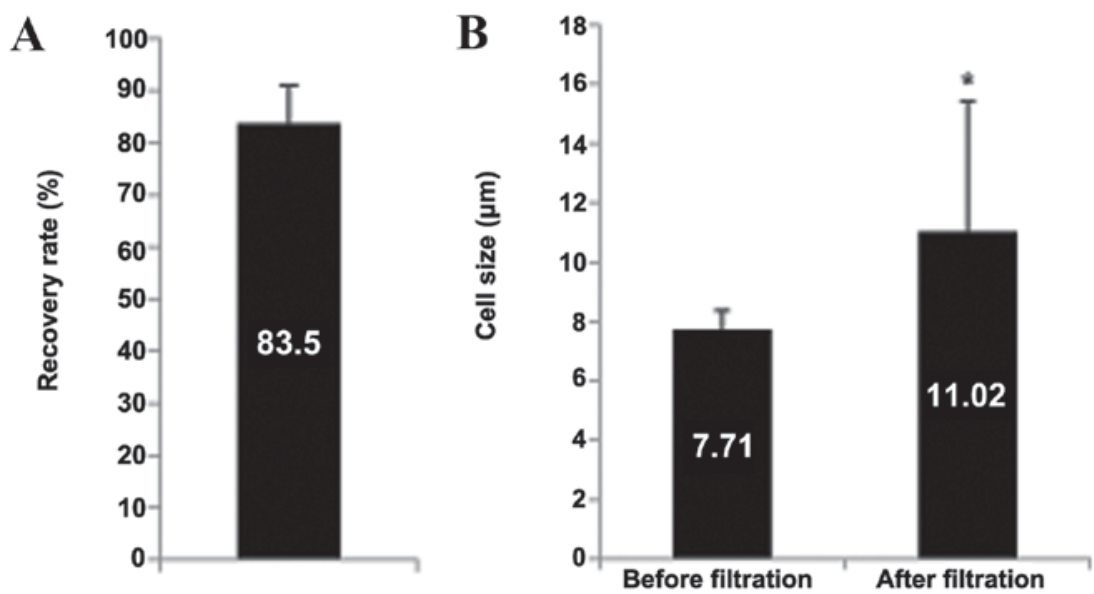

Figure 1. Efficiency of circulating tumor cell (CTC) isolation (A) CTC recovery rate following the spike-in test using healthy volunteer blood samples and H358-GFP cells. (B) Comparison of CTC size prior to and following high-density microporous chip filtration "P=0.03.

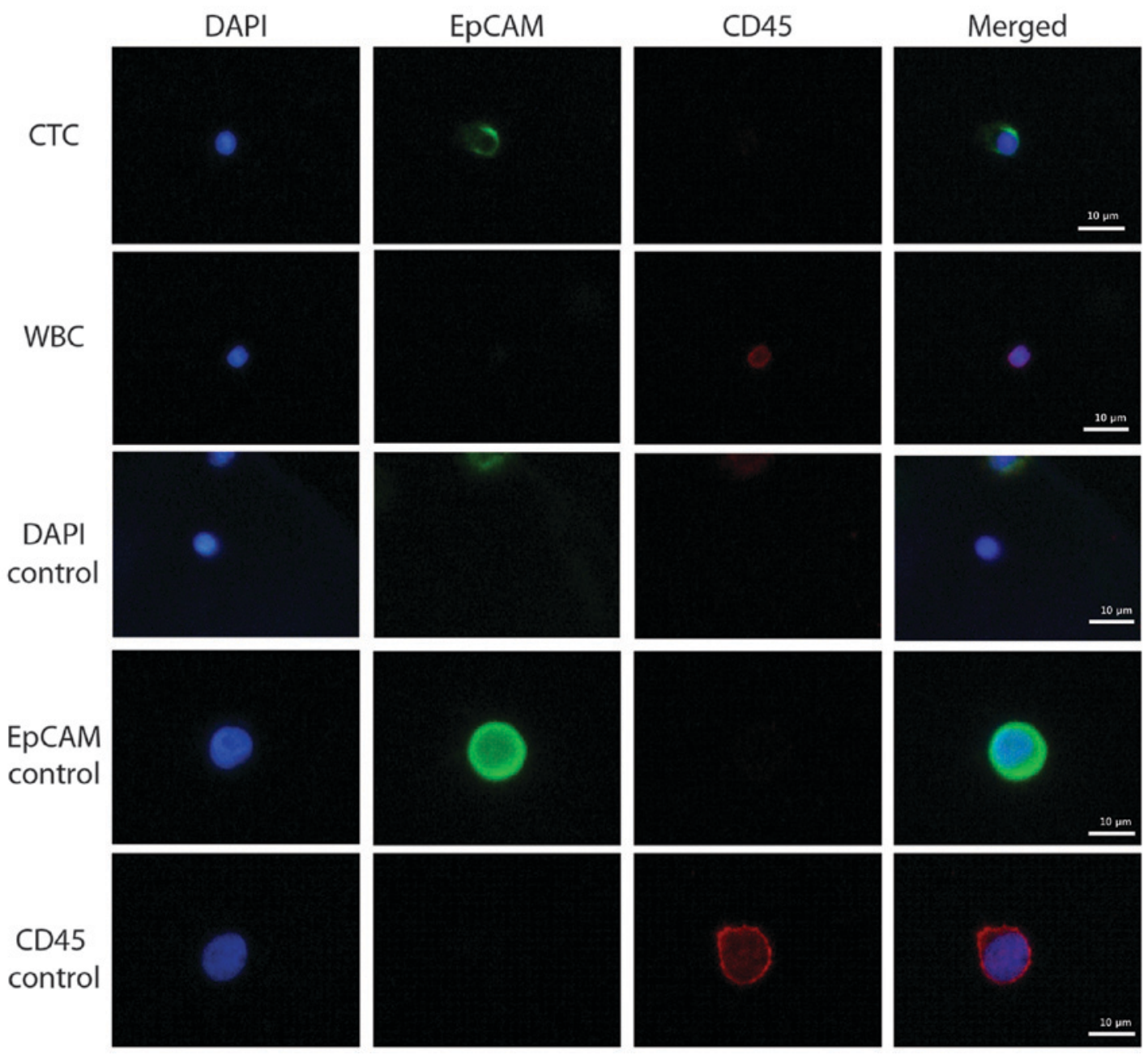

Figure 2. Representative images of immunofluorescent staining of CTCs from patients with breast cancer. DAPI, 4',6-diamidino-2-phenylindole; EpCAM, epithelial cell adhesion molecule; CD, cluster of differentiation; CTC, circulating tumor cell; WBC, white blood cell.

Cancer gene panel analysis of CTCs from patients with breast cancer. Cancer gene panel analysis was performed using the Ion Ampliseq Cancer Hotspot Panel v2. In total, $\geq 10$ ng of DNA can be analyzed for 2,800 COSMIC mutations across 50 genes using this panel. Mutations in MCF7 breast cancer cells were analyzed as a control, with mutations detected in the following genes: PIK3CA, APC, PTEN, IDH2 and TP53 (data not shown). In patient samples, mutations were detected in the following genes: IDH2, TP53, NRAS, IDH1, PDGFRA, HRAS, STK11, EGFR, PTEN, MLH1, PIK3CA, CDKN2A, KIT and SMARCB1 (Table III). The median allele frequency across all patients and genes was 4 (range, 1.7-100\%). Mutations 
Table III. Cancer gene panel analysis.

\begin{tabular}{|c|c|c|c|c|c|}
\hline Patient & $\begin{array}{c}\text { No. of } \\
\text { EpCAM-positive cells }\end{array}$ & $\begin{array}{l}\text { Mutated } \\
\text { gene }\end{array}$ & $\begin{array}{l}\text { COSMIC } \\
\text { ID no. }\end{array}$ & $\begin{array}{l}\text { Amino acid } \\
\text { mutation }\end{array}$ & $\begin{array}{c}\text { Allele } \\
\text { frequency }(\%)\end{array}$ \\
\hline \multirow[t]{2}{*}{1} & 1 & IDH2 & 33733 & p.R172K & 4 \\
\hline & & TP53 & 43753 & Unknown & 2.7 \\
\hline \multirow[t]{6}{*}{2} & 1 & NRAS & 564 & p.G12D & 21 \\
\hline & & IDH1 & 28747 & p.R132C & 2 \\
\hline & & PDGFRA & 22413 & p.V824V & 57.6 \\
\hline & & HRAS & 249860 & p.H27H & 100 \\
\hline & & IDH2 & 33733 & p.R172K & 4 \\
\hline & & STK11 & 21378 & p.T32T & 48.6 \\
\hline \multirow[t]{6}{*}{3} & 1 & EGFR & 27110 & p.V786M & 1.8 \\
\hline & & PTEN & 23626 & p.N323fs*2 & 2.3 \\
\hline & & PTEN & 4994 & p.T321fs*3 & 2.3 \\
\hline & & PTEN & 4990 & p.N323fs"2 & 2.3 \\
\hline & & STK11 & 25851 & p.L282fs"3 & 4.9 \\
\hline & & STK11 & 21360 & p.F354L & 62.5 \\
\hline \multirow[t]{2}{*}{4} & 1 & TP53 & 44547 & p.G226D & 1.7 \\
\hline & & STK11 & 25851 & p.L282fs*3 & 18.1 \\
\hline \multirow[t]{3}{*}{5} & 3 & MLH1 & 26085 & p.V384D & 51.6 \\
\hline & & PIK3CA & 14052 & p.K111R & 1.8 \\
\hline & & STK11 & 25851 & p.L282fs*3 & 3.8 \\
\hline \multirow[t]{2}{*}{6} & 0 & CDKN2A & 14253 & p.H66R & 53.5 \\
\hline & & IDH2 & 33733 & p.R172K & 2 \\
\hline \multirow[t]{2}{*}{7} & 1 & KIT & 28026 & p.M541L & 48.2 \\
\hline & & SMARCB 1 & 1090 & Unknown & 35.1 \\
\hline \multirow[t]{3}{*}{8} & 3 & PTEN & 23626 & p.N323fs*2 & 2.8 \\
\hline & & PTEN & 4994 & p.T321fs*3 & 2.8 \\
\hline & & PTEN & 4990 & p.N323fs ${ }^{*} 2$ & 2.8 \\
\hline 9 & 19 & & N/A & & \\
\hline 10 & 6 & HRAS & 249860 & p.H27H & 84.6 \\
\hline 11 & 7 & KIT & 21983 & p.K546K & 52.9 \\
\hline
\end{tabular}

EpCAM, epithelial cell adhesion molecule; COSMIC, catalogue of somatic mutations in cancer; fs*, insertion-frameshift.

with allele frequencies of between 2 and $5 \%$ were considered CTC-specific mutations and mutations with frequencies $>50 \%$ were considered germline mutations. Although patient 6 tested negative for EpCAM-positive CTCs, COSMIC mutations were detected in the sample. However, patient 9 tested negative for all COSMIC mutations despite having the highest number of EpCAM-positive cells: ERBB4, FGFR3, APC, CSF1R, FGFR1, RET, FLT3 and STK11 (not included in COSMIC and data not shown).

\section{Discussion}

CTC isolation technologies are based upon the physical or biological properties of CTCs. CELLSEARCH ${ }^{\circledR}$, the first and only US Food and Drug Administration approved system, captures CTCs using antibodies directed against EpCAM, and defines CTCs as CK8, 18 or 19-positive and CD45-negative cells (3). Therefore, this technology may isolate fewer differentiated tumor cells. Rao et al (10) reported that the expression of EpCAM in carcinoma cells decreases during epithelial-mesenchymal transition. Furthermore, a recent report demonstrated that there are CTCs that do not express EpCAM; therefore, EpCAM-based isolation technology may fail to detect certain CTCs (11). The technique used in the present study was able to isolate EpCAM-negative CTCs using size-based filtration. In patient 6, no EpCAM-positive cells were observed but mutations in CDKN2A and IDH2 genes were detected (Table III), indicating that there are EpCAM-negative CTCs in patients with breast cancer.

The rarity of CTCs makes it difficult to obtain sufficient amounts of DNA for analysis. Therefore, high purity enrichment of CTCs from mixed cell populations is required for DNA amplification using WGA. In the present study, 0-19 CTCs/5 ml blood sample were detected (Table II) and 




Patient 3
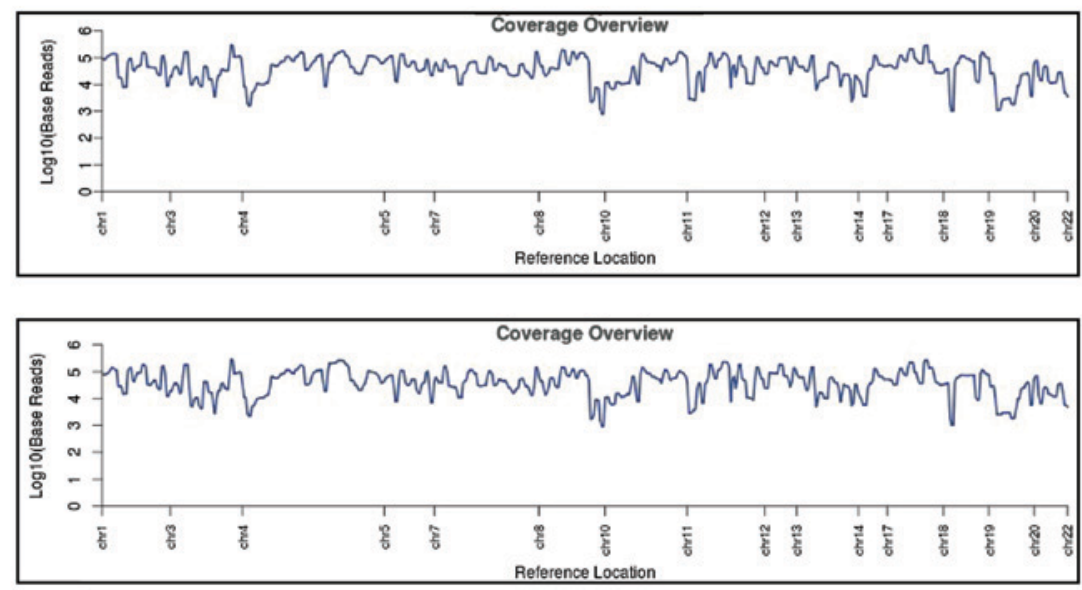

Patient 5

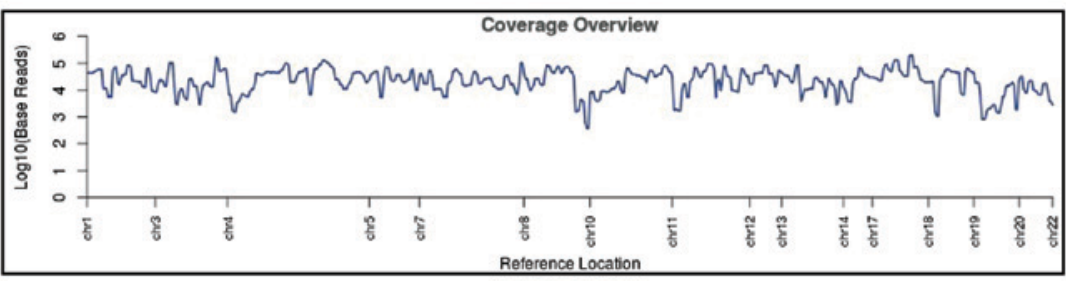

Patient 8

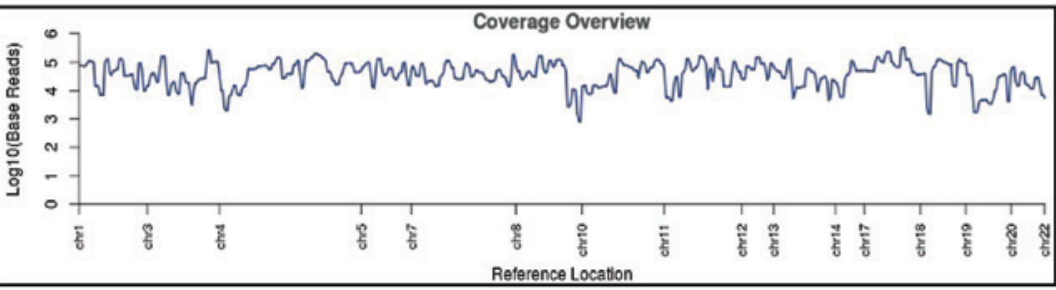

Figure 3. Reference coverage of reads following whole genome amplification.

the amount of DNA following amplification was sufficient to carry out cancer gene panel analysis (Table III). The present study evaluated a novel approach to CTC isolation and demonstrated that it is applicable to the genomic analysis of CTCs from patients with breast cancer.

Previous studies have reported several genetic mutations, including HER2, BRCA, PIK3CA, TP53, GATA3 and PTEN in patients with breast cancer (20-25). In the present study, mutations were detected in TP53, PIK3CA and PTEN in the CTCs of patients with breast cancer, suggesting that genomic analysis was successful. COSMIC mutations were identified in 10/11 patients; however, no COSMIC mutations were detected in patient 9, who had 19 EpCAM-positive cells (Table III). Although no COSMIC mutations were observed in patient 9, mutations were identified in the following genes: ERBB4, FGFR3, APC, CSF1R, FGFR1, RET, FLT3 and STK11. Among them, APC, FGFR1, TP53 and SKT11 mutations have previously been reported as driver mutations in breast cancer (26). Further investigation with a larger cohort of patients may provide useful information about the genetic mutations associated with breast cancer and aid in the development of therapeutic strategies for the treatment of this disease.

Liquid biopsies, followed by molecular profiling of the CTCs isolated, may have applications in cancer diagnosis, prediction of recurrence and metastasis, and aid in therapy decision-making. In addition, CTCs can be obtained in a non-invasive and reproducible manner. In conclusion, the present study evaluated a novel approach to CTC isolation and demonstrated its application in the genomic analysis of CTCs from patients with breast cancer.

\section{Acknowledgements}

The present study was supported by the National Research and Development Program of the Ministry of Trade, Industry and Energy of Korea (grant no. 10045947). In addition, the authors would like to thank Enago (www.enago.co.kr) for reviewing the English language of the present study. 


\section{References}

1. Pukazhendhi G and Glück S: Circulating tumor cells in breast cancer. J Carcinog 13: 8, 2014.

2. Alix-Panabieres $\mathrm{C}$ and Pantel K: Challenges in circulating tumor cell research. Nat Rev Cancer 14: 623-631, 2014.

3. Pantel K, Alix-Panabières $\mathrm{C}$ and Riethdorf S: Cancer micrometastases. Nat Rev Clin Oncol 6: 339-351, 2009.

4. Pantel K and Alix-Panabières C: Real-time liquid biopsy in cancer patients: Fact or fiction? Cancer Res 73: 6384-6388, 2013.

5. Ilie M, Hofman V, Long E, Bordone O, Selva E, Washetine K, Marquette $\mathrm{CH}$ and Hofman P: Current challenges for detection of circulating tumor cells and cell-free circulating nucleic acids, and their characterization in non-small cell lung carcinoma patients. What is the best blood substrate for personalized medicine? Ann Transl Med 2: 107, 2014.

6. Alix-Panabieres $\mathrm{C}$ and Pantel K: The circulating Tumor Cells: liquid biopsy of cancer. Klin Lab Diagn 4: 60-64, 2014 (In Russian).

7. Allard WJ, Matera J, Miller MC, Repollet M, Connelly MC, Rao C, Tibbe AG, Uhr JW and Terstappen LW: Tumor cells circulate in the peripheral blood of all major carcinomas but not in healthy subjects or patients with nonmalignant diseases. Clin Cancer Res 10: 6897-6904, 2004.

8. Sestier C, Lacava ZGM, Lacava LM, Da Silva MF and Azevedo RB: In vitro toxicity of magnetic fluids evaluated for macrophage cell lines. J Magn Magn Mater 252: 403-405, 2002.

9. Tiwari A, Punshon G, Kidane A, Hamilton G and Seifalian AM: Magnetic beads (Dynabead) toxicity to endothelial cells at high bead concentration: Implication for tissue engineering of vascular prosthesis. Cell Biol Toxicol 19: 265-272, 2003.

10. Rao CG, Chianese D, Doyle GV, Miller MC, Russell T, Sanders RA Jr and Terstappen LW: Expression of epithelial cell adhesion molecule in carcinoma cells present in blood and primary and metastatic tumors. Int J Oncol 27: 49-57, 2005.

11. Sieuwerts AM, Kraan J, Bolt J, van der Spoel P, Elstrodt F, Schutte M, Martens JW, Gratama JW, Sleijfer S and Foekens JA: Anti-epithelial cell adhesion molecule antibodies and the detection of circulating normal-like breast tumor cells. J Natl Cancer Inst 101: 61-66, 2009.

12. Johnson RH, Chien FL and Bleyer A: Incidence of breast cancer with distant involvement among women in the United States, 1976 to 2009. JAMA 309: 800-805, 2013.

13. Vogel CL, Cobleigh MA, Tripathy D, Gutheil JC, Harris LN, Fehrenbacher L, Slamon DJ, Murphy M, Novotny WF, Burchmore M, et al: Efficacy and safety of trastuzumab as a single agent in first-line treatment of HER2-overexpressing metastatic breast cancer. J Clin Oncol 20: 719-726, 2002.

14. Spector NL, Xia W, Burris H III, Hurwitz H, Dees EC, Dowlati A, O'Neil B, Overmoyer B, Marcom PK, Blackwell KL, et al: Study of the biologic effects of lapatinib, a reversible inhibitor of ErbB1 and ErbB2 tyrosine kinases, on tumor growth and survival pathways in patients with advanced malignancies. J Clin Oncol 23 2502-2512. 2005.
15. Fernandez SV, Bingham C, Fittipaldi P, Austin L, Palazzo J, Palmer G, Alpaugh K and Cristofanilli M: TP53 mutations detected in circulating tumor cells present in the blood of metastatic triple negative breast cancer patients. Breast Cancer Res 16: 445, 2014.

16. Pestrin M, Salvianti F, Galardi F, De Luca F, Turner N, Malorni L, Pazzagli M, Di Leo A and Pinzani P: Heterogeneity of PIK3CA mutational status at the single cell level in circulating tumor cells from metastatic breast cancer patients. Mol Oncol 9: 749-757, 2015.

17. American Joint Committee on Cancer: AJCC Cancer Staging Manual. 7th edition, Springer, New York, NY, 2010.

18. Kim EH, Lee JK, Kim BC, Rhim SH, Kim JW, Kim KH, Jung SM, Park PS, Park HC, Lee J and Jeon BH: Enrichment of cancer cells from whole blood using a microfabricated porous filter. Anal Biochem 440: 114-116, 2013.

19. Columns FA, van Dalum G, Beck M and Terstappen LW: Filter characteristics influencing circulating tumor cell enrichment from whole blood. PLoS One 8: e61770, 2013.

20. Kallioniemi OP, Kallioniemi A, Kurisu W, Thor A, Chen LC, Smith HS, Waldman FM, Pinkel D and Gray JW: ERBB2 amplification in breast cancer analyzed by fluorescence in situ hybridization. Proc Natl Acad Sci USA 89: 5321-5325, 1992.

21. Gretarsdottir S, Thorlacius S, Valgardsdottir R, Gudlaugsdottir S, Sigurdsson S, Steinarsdottir M, Jonasson JG, Anamthawat-Jonsson K and Eyfjörd JE: BRCA2 and p53 mutations in primary breast cancer in relation to genetic instability. Cancer Res 58: 859-862, 1998.

22. Janku F, Wheler JJ, Westin SN, Moulder SL, Naing A, Tsimberidou AM, Fu S, Falchook GS, Hong DS, Garrido-Laguna I, et al: PI3K/AKT/mTOR inhibitors in patients with breast and gynecologic malignancies harboring PIK3CA mutations. J Clin Oncol 30: 777-782, 2012.

23. Arnold JM, Choong DY, Thompson ER; kConFab, Waddell N, Lindeman GJ, Visvader JE, Campbell IG and Chenevix-Trench G: Frequent somatic mutations of GATA3 in non-BRCA1/BRCA2 familial breast tumors, but not in BRCA1-, BRCA2- or sporadic breast tumors. Breast Cancer Res Treat 119: 491-496, 2010.

24. $\mathrm{Hu} \mathrm{T}$ and $\mathrm{Li} \mathrm{C}$ : Convergence between Wnt- $\beta$-catenin and EGFR signaling in cancer. Mol Cancer 9: 236, 2010.

25. Augello MA, Burd CJ, Birbe R, McNair C, Ertel A, Magee MS, Frigo DE, Wilder-Romans K, Shilkrut M, Han S, et al: Convergence of oncogenic and hormone receptor pathways promotes metastatic phenotypes. J Clin Invest 123: 493-508, 2013.

26. Stephens PJ, Tarpey PS, Davies H, Van Loo P, Greenman C, Wedge DC, Nik-Zainal S, Martin S, Varela I, Bignell GR, et al: The landscape of cancer genes and mutational processes in breast cancer. Nature 486: 400-404, 2012. 